xét nghiệm cận lâm sàng cần có để có thể chẩn đoán chính xác bệnh lao. Bên cạnh đó vẫn còn một số kiến thức có tỉ lệ trả lời đúng thấp như: phân biệt người nhiễm lao và người mắc bệnh lao, về số mầu đờm cần lấy để chẩn đoán bệnh. Vì vậy cần cung cấp thêm thông tin của những khía cạnh này cho các bác sĩ công tác tại trạm y tế xã.

\section{KẾT LUẬN}

Độ tuổi trung bình của các bác sĩ tại TYT là $40,3 \pm 9,2$, thâm niên công tác trung bình là $15,3 \pm 9,2$, số lượng bác sĩ nữ và bác sĩ nam là tương đương nhau (49,3\% so với 50,7\%).

Kiến thức cơ bản về bệnh lao của bác sĩ tại TYT là tương đối cao. Trong đó các kiến thức về phân loại, nguyên nhân gây bệnh, đường lây có hầu hết các bác sĩ đã trả lời đúng với tỉ lệ lần lượt là: $99,7 \%, 97 \%$ và $97,3 \%$.

Các bác sĩ công tác tại TYT đã nắm được các kiến thức về triêu chứng và xét nghiệm cận lâm sàng cần làm để chẩn đoán bệnh lao. Tuy nhiên, chỉ có $54,6 \%$ bác sĩ trả lời đúng cần lấy ba mẫu đờm để chẩn đoán bệnh lao.

Chưa thấy sự khác biệt về các kiến thức cơ bản của bệnh lao theo nhóm tuổi, giới tính và thâm niên công tác.

\section{TÀI LIÊU THAM KHẢO}

1. World Health Organaization (2019), Global tuberculosis report 2019, 52-59.

2. Bộ Y tế (2020). Hưởng ứng Ngày Thế giới phòng chống lao 24/3/2020, tổng kết hoạt động phòng chống lao năm 2019 và triển khai kế hoạch năm 2020.

3. Malangu N. và Adebanjo O.D. (2015). Knowledge and practices about multidrug-resistant tuberculosis amongst healthcare workers in Maseru. Afr J Prim Health Care Fam Med, 7(1).

4. Buregyeya E., Kasasa S., và Mitchell E.M.H. (2016). Tuberculosis infection control knowledge and attitudes among health workers in Uganda: a cross-sectional study. BMC Infect Dis, 16(1), 416.

5. Nguyến Phương Hoa (2005). Diagnosis and treatment of pulmonary tuberculosis at basic health care facilities in rural Vietnam: a survey of knowledge and reported practices among health staff.

6. Woith W.M, Volchenkov G and Larson J.L (2010). Russian healthcare workers' knowledge of tuberculosis and infection control. Int J Tuberc Lung Dis Off J Int Union Tuberc Lung Dis, 14(11), 1489-1492.

7. Mustafa T, Shahzad Y and Kiani A (2018). A survey of knowledge, attitude, and practices of private retail pharmacies staff in tuberculosis care: study from Dera Ismail Khan City, Pakistan. J Pharm Policy Pract, 11, 7. 42-47.

8. Shrestha A, Bhattarai D, Thapa B et al. (2017). Health care workers' knowledge, attitudes and practices on tuberculosis infection control, Nepal. BMC Infect Dis, 17(1), 724-731.

\title{
ĐĂC ĐIỂM HÌNH ẢNH CộNG HƯỞNG TỪ CỦA U MÀNG NÃO Ở NGƯỜI LỚN
}

\author{
Nguyễn Hữu Hoạt ${ }^{1}$, Nguyễn Xuân Khái ${ }^{2}$, \\ Ngô Tuấn Minh², Nguyễn Việt Dũng ${ }^{2}$, Trần Công $\mathrm{Hoan}^{3}$
}

\section{TÓM TẮT}

Mục đích: Đánh giá đặc điểm hình ảnh công hưởng từ (CHT) của u màng não (UMN) ở người lớn. Đối tượng và phương pháp nghiên cứu: Nghiên cứu hồi cứu kết hợp tiến cứu, mô tả cắt ngang 76 bênh nhân với 81 khối u được chẩn đoán, phâu thuât và có kết quả mô bệnh học là UMN tại khoa Phấu thuật thần kinh, Bệnh viện Việt Đức và Bệnh viên Quân y 103 trong thời gian từ tháng 10/2020 đến tháng 03/2021. Kết quả: Phần lớn là u đơn độc $(96,1 \%)$, bờ đều $(67,9 \%)$, kích thước trung bình $40,19 \pm 16,45 \mathrm{~mm}$. Khối u đồng tín hiệu trên T1W và

${ }^{1}$ Bệnh viện đa khoa Hoàn Mỹ

Bệnh viện Quân y 103

${ }^{3}$ Bềnh viện $E$

Chịu trách nhiệm chính: Nguyễn Việt Dũng

Email: dung.nguyenviet.cdha@gmail.com

Ngày nhận bài: 4.5.2021

Ngày phản biên khoa học: 24.6.2021

Ngày duyệt bài: 5.7.2021 tăng nhe tín hiệu trên T2W, tỷ lệ lần lượt là $66,7 \%$ và $65,4 \%$. Sau tiểm, đa số u ngấm thuốc đồng nhất (79\%), dấu hiệu đuôi màng cứng quan sát thây ở $60,5 \%$ tổng số u. Các thần phần vôi hóa, nang trong $\mathrm{u}$, chảy máu trong u chiếm tỷ lệ lần lượt là $12,3 \%$, $2,5 \%$ và $16,0 \%$. Phù não quanh u găp ở $59,3 \%$. Tỷ lế chèn ép động mạch, chèn ép xoang tĩnh mạch và chèn ép thần kinh lần lướt là $22,2 \%, 38,3 \%$ và $28,4 \%$. Có 9,9\% số khối u có biến đổi xương cạnh u. Kết luân: CHT là phương pháp chẩn đoán hình ảnh có giá trị cao trong chẩn đoán UMN cũng như đánh giá mức độ xâm lấn các tổ chức xung quanh $u$, giúp ích cho chẩn đoán và tiên lượng.

Tư khóa: Cộng hưởng từ, u màng não.

\section{SUMMARY}

MAGNETIC RESONANCE IMAGING FEATURES OF MENINGIOMAS IN ADULTS

Objectives: Evaluate magnetic resonance imaging (MRI) characteristics of meningioma in adults. Subjects and methods: Retrospective combined with prospective research, cross-sectional description 
of 76 patients with 81 diagnosed tumors, surgical and histopathological results of meningioma in the Department of Neurosurgery, Viet Duc Hospital and Military Hospital 103 during the period from October 2020 to March 2021. Results: Most are solitary tumors $(96.1 \%)$, well-differentiated $(67.9 \%)$, average size $40.19 \pm 16.45 \mathrm{~mm}$. Tumor iso-intense on T1W and slightly hyper-intense on $\mathrm{T} 2 \mathrm{~W}$, and the rates are $66.7 \%$ and $65.4 \%$, respectively. After injection, most tumors enhanced homogeneous $(79 \%)$, the epidural tail was observed in $60.5 \%$ of all tumors. The calcification, cysts in the tumor, bleeding in the tumor accounted for $12.3 \%, 2.5 \%$, and $16.0 \%$, respectively. Brain edema around tumors was found in $59.3 \%$. The rates of arterial compression, venous sinus compression, and nerve compression were $22.2 \%$, $38.3 \%$, and $28.4 \%$, respectively. $9.9 \%$ of tumors have bone lesions. Conclusion: MRI is a precious diagnostic imaging method in diagnosing meningioma and evaluating the extent of invasiveness around the tumor, helping with diagnosis and prognosis.

Keywords: Magnetic resonance, meningioma.

\section{I. ĐĂT VẤN ĐỀ}

UMN là loại u xuất phát từ nhung mao của màng nhện, phần lớn là lành tính, là những khối u hay gặp sau u tế bào hình sao. Theo Black, tại Hoa Kỳ, UMN chiếm tỷ lệ khoảng $25 \%$ các khối u trong sọ, phổ biến nhất trong các loại u không phải tế bào hình sao. Biểu hiện lâm sàng của UMN rất đa dạng, phụ thuộc vào vị trí của khối u. Do đó, việc chẩn đoán UMN không thể chỉ dựa trên lâm sàng mà cần phải kết hợp các phương pháp hình ảnh học khác.

Chẩn đoán hình ảnh UMN bao gồm cắt lớp vi tính (CLVT) và CHT (CHT). Tuy nhiên, CLVT hạn chế trong các tổn thương nhỏ vùng hố sau do nhiễu xương và khó đánh giá xâm lấn của khối. Do đó, $\mathrm{CHT}$ là phương pháp được lựa chọn hàng đầu trong đánh giá u màng não, khắc phục được các nhược điểm của CLVT nhờ các đặc điểm: độ phân giải cao, phân biệt tốt tổn thương trong trục và ngoài trục, có thể quan sát nhiêu hướng trong không gian. Vì vậy chúng tôi tiến hành nghiên cứu này với mục tiêu: "Nhận xét đặc điểm hình ảnh cộng hưởng từ của u màng não ở người lớn", qua đó giúp chẩn đoán và đưa ra kết hoạch điều trị sớm, góp phần nâng cao hiệu quả điều trị.

\section{II. ĐỐI TƯỢNG VÀ PHƯƠNG PHÁP NGHIÊN CỨU}

1. Đối tượng nghiên cứu: gồm 76 bệnh nhân với 81 khối u được chẩn đoán, phẫu thuật và có kết quả mô bệnh học là UMN tại khoa Phẫu thuật thần kinh, Bệnh viện Việt Đức và Bệnh viện Quân y 103 trong thời gian từ tháng 10/2020 đến tháng 03/2021.

2. Phương pháp nghiên cứu: Mô tả cắt ngang.
*Bệnh nhân được chụp CHT 1,5 Tesla sọ não với các chuối xung axial và sagittal T1 FSE, axial T2 FSE, axial FLAIR, axial DWI, axial T2*, axial và coronal $\mathrm{T} 1 \mathrm{GE}$ sau tiêm đối quang từ (Gadolinium liều 0,1 mmol/kg cân nặng).

*Các biến số dùng trong NC: đặc điểm trực tiếp của khối u (số lượng, vị trí, kích thước, đường bờ, tín hiệu trên T1, T2, DWI, đặc điểm ngấm thuốc đối quang từ, vôi hóa, chảy máu trong $u$ ) và dấu hiệu gián tiếp của khối u (tình trạng biến đổi xương, chèn ép xoang tĩnh mạch, động mạch, thần kinh, tình trạng phù não, đè đẩy đường giữa, đè đầy não thất, dấu hiệu đuôi màng cứng).

*Các tiêu chuẩn dùng trong $\mathrm{NC}$ :

- Tín hiệu tổn thương được lấy để mô tả là tín hiệu của vùng lớn nhất trong tổn thương và so với nhu mô não lân cận.

- Kích thước khối u được đo trên hình ảnh T1 sau tiêm, ở lát cắt mà kích thước khối u lớn nhất. Tổn thương được đo từ mép ngoài đến mép ngoài.

- Tình trạng biến đổi xương: bản xương sọ cạnh khối dày lên, hoặc bị phá huỷ.

- Tình trạng chèn ép xoang tĩnh mạch, động mạch, thần kinh: UMN được đánh giá là chèn ép khi ranh giới không rõ với xoang tĩnh mạch, động mạch và thần kinh.

- Phù não: là viền tăng tín hiệu quanh khối trên T2 hoặc FLAIR. Phù độ I: dưới $2 \mathrm{~cm}$, phù độ II: từ $2 \mathrm{~cm}$ đến một bán cầu, phù độ III: phù trên 1 bán cầu.

- Đẩy lệch đường giữa: độ $1:$ dưới $5 \mathrm{~mm}$, độ 2: từ 5 đến $10 \mathrm{~mm}$, độ $3:$ trên $10 \mathrm{~mm}$.

- Đè đẩy não thất: u chèn ép gây thay đổi hình dạng não thất.

- Dấu hiệu đuôi màng cứng: dày màng cứng cạnh u và ngấm thuốc sau tiêm.

\section{KẾT QUẢ NGHIÊN CỨU}

\section{1. Đắc điểm chung:}

Bảng 1 Đặc điểm chung của đôî tượng nghiên cứu $(n=76)$

\begin{tabular}{|c|c|c|c|}
\hline \multicolumn{2}{|c|}{ Đăc điếm } & $\mathbf{n}$ & $\%$ \\
\hline \multirow{3}{*}{ Tuổi } & $<40$ & 10 & 13,2 \\
\hline & $\geq 40$ & 66 & 86,8 \\
\hline & \multicolumn{3}{|c|}{ Trung bình: $56,58 \pm 13,34$} \\
\hline \multirow{2}{*}{ Giới } & Nam & 58 & 76,3 \\
\hline & Nũ̃ & 18 & 23,7 \\
\hline \multirow{3}{*}{$\begin{array}{c}\text { Triệu } \\
\text { chứng } \\
\text { lâm sàng }\end{array}$} & Đau đầu & 55 & 72,4 \\
\hline & Rối loạn vận động & 12 & 15,8 \\
\hline & Mờ mắt & 11 & 14,5 \\
\hline
\end{tabular}

Nhận xét: Trong nhóm NC, độ tuổi trung bình là $56,58 \pm 13,34$ tuổi, đa số gặp ở BN nữ, 
tỷ lệ nữ/nam là 3,22/1. Triệu chứng hay gặp nhất trong nhóm nghiên cứu là đau đầu với $55 / 76$ BN chiếm $72,4 \%$.

\section{2. Đặc điểm hình ảnh cộng hưởng từ}

\subsection{Dấu hiệu trực tiếp}

- Đa số trường hợp là UMN đơn độc, 73/76 BN chiếm tỷ lệ $96,1 \%$. Vị trí hay gặp nhất là u vòm so với 45/81 khối u, chiếm tỷ lệ 55,5\%.

- Kích thước trung bình của khối u trong nghiên cứu là 40,19 $\pm 16,45 \mathrm{~mm}$. Trong đó, đa số u có kích thước từ $3-6 \mathrm{~cm}$, chiếm tỷ lệ $64,2 \%$.

- Đa số u có bờ đều, chiếm tỷ lệ $67,9 \%$.

Bảng 2 Đặc điểm tín hiệu trên hình ảnh $\mathrm{CHT}(\mathrm{n}=81)$

\begin{tabular}{|c|c|c|c|}
\hline \multicolumn{2}{|c|}{ Đặc điếm tín hiệu } & $\mathbf{n}$ & $\%$ \\
\hline \multirow{3}{*}{ T1W } & Đồng tín hiệu & 54 & 66,7 \\
\cline { 2 - 4 } & Tăng tín hiệu & 0 & 0 \\
\cline { 2 - 4 } & Giảm tín hiệu & 27 & 33,3 \\
\hline \multirow{3}{*}{ T2W } & Đồng tín hiệu & 26 & 32,1 \\
\cline { 2 - 4 } & Tăng tín hiệu & 53 & 65,4 \\
\cline { 2 - 4 } & Giảm tín hiệu & 2 & 2,5 \\
\hline \multirow{3}{*}{ DWI } & Hạn chế khuếch tán & 42 & 51,9 \\
\cline { 2 - 4 } & $\begin{array}{c}\text { Không hân chế } \\
\text { khuếch tán }\end{array}$ & 39 & 48,1 \\
\hline \multirow{2}{*}{$\begin{array}{c}\text { Ngấm } \\
\text { thuốc }\end{array}$} & Đồng nhất & 64 & 79,0 \\
\cline { 2 - 4 } & Không đồng nhất & 17 & 21,0 \\
\hline
\end{tabular}

Nhân xét: Trên hình ảnh T1W: đa số khối u đồng tín hiêuu với nhu mô não lân cận chiếm $66,7 \%$, không có trường hợp nào tăng tín hiệu trên T1W. Trên hình ảnh T2W: 65,4\% khối u có tăng tín hiệu trên $\mathrm{T} 2 \mathrm{~W}$. Tỷ lệ giảm tín hiệu trên T2W chỉ có $2,5 \%$. Tỷ lệ UMN có hạn chế khuếch tán trên hình ảnh DWI trong nghiên cứu là $48,1 \%$. Tất cả các khối u đều ngấm thuốc. Trong đó, đa số ngấm thuốc đồng nhất (64/81 khối u chiếm tỷ lệ $79 \%$ ).

Bảng 3. Đặc điểm biến đổi trong u ( $n=81)$

\begin{tabular}{|c|c|c|}
\hline Đặc điểm & $\mathbf{n}$ & $\mathbf{\%}$ \\
\hline Vôi hóa trong u & 10 & 12,3 \\
\hline Nang trong u & 2 & 2,5 \\
\hline Chảy máu trong u & 13 & 16,0 \\
\hline
\end{tabular}

Nhận xét: Tỷ lệ khối u có thành phần vôi hóa, thành phần nang trong u lần lượt là $12,3 \%$ và $2,5 \%$. Chảy máu trong u gặp ở 13/81 khối u, chiếm tỷ lệ 16\%.

\subsection{Dấu hiệu gián tiếp của khôii u}

Bảng 4 Mức độ chèn ép của khôi u (n=81)

\begin{tabular}{|c|c|c|c|}
\hline \multicolumn{2}{|c|}{ Đặc điểm } & $\mathbf{n}$ & $\mathbf{\%}$ \\
\hline \multirow{3}{*}{$\begin{array}{c}\text { Mức độ } \\
\text { phù } \\
\text { não }\end{array}$} & Không phù não & 33 & 40,7 \\
\cline { 2 - 4 } & Phù não độ 1 & 25 & 30,9 \\
\cline { 2 - 4 } & Phù não đồ 2 & 20 & 24,7 \\
\hline Phù não độ 3 & 3 & 3,7 \\
\hline $\begin{array}{c}\text { Mức độ } \\
\text { đè đầy }\end{array}$ & $\begin{array}{c}\text { Không đè đấy đường } \\
\text { giữa }\end{array}$ & 50 & 61,7 \\
\hline
\end{tabular}

\begin{tabular}{|c|c|c|c|}
\hline \multirow{3}{*}{ đường } & $<5 \mathrm{~mm}$ & 13 & 16,0 \\
\cline { 2 - 4 } giữa & $5-10 \mathrm{~mm}$ & 7 & 8,6 \\
\cline { 2 - 4 } & $>10 \mathrm{~mm}$ & 11 & 13,6 \\
\hline Chèn ép & Có & 41 & 50,6 \\
\cline { 2 - 4 } não thất & Không & 40 & 49,4 \\
\hline
\end{tabular}

Nhân xét: Trong nhóm NC, có 40,7\% tổng số u không gây phù não quanh u. Trong những khối u gây phù não, đa số gặp phù não độ 1 , độ 2 (chiếm tỳ lệ $55,6 \%$ tổng số khối u). Đa sổ UMN không gây đè đẩy đường giữa, chiếm tỷ lệ $61,7 \%$. Có $11 / 81$ khối u đẩy lệch đường > 10 mm, chiếm tỷ lệ 13,6\%. Tỷ lệ UMN chèn ép não thất trong NC gặp ở 41/81 trường hợp, chiếm tỷ lệ $50,6 \%$.

Bảng 5. Đặc điểm chèn ép tổ chức cạnh $u(n=81)$

\begin{tabular}{|c|c|c|}
\hline Đặc điểm & $\mathbf{n}$ & $\mathbf{\%}$ \\
\hline Biến đối xương cạnh u & 8 & 9,9 \\
\hline Chèn ép xoang tĩnh mạch & 31 & 38,3 \\
\hline Chèn ép động mạch & 18 & 22,2 \\
\hline Chèn ép thần kinh & 23 & 28,4 \\
\hline
\end{tabular}

Nhận xét: Trong NC, UMN đa số không gây biến đổi xương cạnh u, chiếm tỷ lệ $90,1 \%$. Có $31 / 81$ khối u có chèn ép xoang tĩnh mach, chiếm tỷ lệ $38,3 \%$. Tỷ lê UMN chèn ép mạch máu và thần kinh lần lượt là $22,2 \%$ và $28,4 \%$.

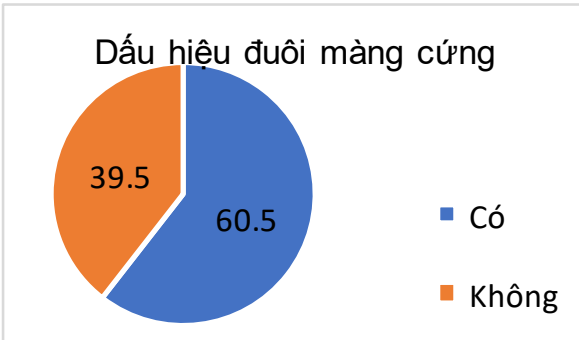

Biểu đồ 1 Dâu hiệu đuôi màng cứng $(n=81)$

Nhận xét: Trong NC, UMN có dấu hiệu đuôi màng cứng chiếm tỷ lệ 60,5\%.

\section{BÀN LUÂ̂N}

1. Đặc điểm trực tiếp của khối u. Đa số trường hợp UMN là u đơn độc (chiếm 96,1\%). Theo Lê Thị Hồng Phương (2016), tỷ lệ BN có UMN đơn độc là $94,7 \%$ [1]. UMN trong nhóm NC hay gặp nhất ở vòm sọ (45/81 khối u chiếm tỷ lệ $55,5 \%)$. Kết quả này tương tự kết quả NC của Trân Văn Việt (2011), trong đó tỷ lệ UMN vòm sọ là 52,3\% [2]. Theo Nguyễn Minh Thuận (2019), UMN vị trí thái dương và chẩm có tỷ lệ thấp hơn lần lượt là $16,2 \%$ và $5,4 \%$ [3].

Đa số khối u có kích thước trong khoảng từ 3 $-6 \mathrm{~cm}$, chiếm tỷ lệ $64,2 \%$. Theo Nguyễn Minh Thuận (2019), tỳ lệ u có kích thước từ $3-6 \mathrm{~cm}$ là $56 \%$, cao hơn so với 2 nhóm còn lại [3], Trần 
Văn Việt (2011) tỷ lệ này là $50 \%$ [2]. UMN có kích thước lớn thường ở các vị trí như vòm sọ, liềm não và cạnh đường giữa. Các u nhỏ đa số nằm ở vị trí nền so và hố yên. Có thể giải thích là nền sọ có nhiều cấu trúc thần kinh mạch máu nên u kích thước nhỏ đã có thể gây triệu chứng lâm sàng. Kích thước trung bình của khối u trong NC là 40,19 $\pm 16,45 \mathrm{~mm}$. Salah (2019) kích thước trung bình của UMN ở nhóm lành tính và nhóm ác tính lần lượt là 40,0 mm và 55,7 mm [4]. Kết quả này tương đương với NC của chúng tôi.

Hình ảnh điển hình của UMN: đồng tín hiệu hoặc giảm nhẹ tín hiệu so với chất xám lân cận trên hình ảnh $T 1 W$, đồng hoặc tăng nhẹ tín hiệu so với chất xám lân cận trên hình ảnh T2W [5]. Trong NC của chúng tôi, đa số khối u đồng tín hiệu trên T1W (chiếm tỷ lệ 66,7\%) và tăng nhẹ tín hiệu trên T2W (chiếm tỷ lệ 65,4\%). Kết quả này tương tự với NC của Lê Thị Hồng Phương (2016): 61,4\% khối u đồng tín hiệu trên T1W, $70,2 \%$ khối u tăng tín hiệu trên T2W [1]. UMN cấu tạo chủ yếu bởi chất xơ và hàm lượng nước thấp, do đó thường đồng tín hiệu trên T1W và tăng nhe tín hiệu trên T2W. Điều này trái ngược với các u nội sọ khác, thường giảm tín hiệu vừa phải trên TiW, do tăng hàm lượng nước của các mô tân sinh [6].

Trong nhóm NC, tỷ lệ u có hạn chế khuếch tán là 48,1\%. Theo Lê Thị Hồng Phương (2016), tỷ lệ UMN vùng nền sọ có hạn chế khuếch tán chiếm tỷ lê 47,4\% [1]. Salah và cs (2019), có 29/71 khối u có hạn chế khuếch tán, chiếm tỷ lê $40,8 \%$ [4]. Kết quả này tương đương với NC của chúng tôi. Gần đây, nhiêu NC chứng minh rằng, UMN không điển hình và ác tính có xu hướng tăng tín hiệu trên hình ảnh $D W I$ và cho thây giá trị $A D C$ giảm rõ rệt khi so sánh với nhu mô não bình thường, còn UMN lành tính có xu hướng có giá trị $A D C$ cao hơn so với nhu mô não bình thường [6].

Trong nhóm NC, tất cả các khối u đều ngấm thuốc. Trong đó, đa số ngấm thuốc đồng nhất (64/81 khối u chiếm tỷ lệ 79\%). Zhang và cS (2018), tất cả khối u đều ngấm thuốc tương phản từ sau tiêm, trong đó có 38/142 khối u ngấm thuốc mạnh sau tiêm, chiếm tỷ lệ $26,8 \%$ [7]. Theo Trân Văn Việt (2011), tỳ lệ khối u ngấm thuốc mạnh và đồng nhất sau tiêm là $70 \%$ [2]. UMN ngấm thuốc mạnh và đồng nhất do các mạch máu nuôi u thường xuất phát từ động mạch cảnh trong, xâm nhập vào màng mềm, không qua hàng rào máu não. Điều này giúp phân biệt UMN với các khối u nội sọ khác có mạch máu xuất phát từ các động mạch não. Ngoài ra, hình ảnh CHT có tiêm thuốc giúp tăng khả năng phát hiện những khối u nhỏ, đồng tín hiệu với nhu mô não lân cận. Ngoài ra giúp đánh giá u tái phát hay còn sót sau phẫu thuật và giúp đánh giá tổn thương UMN dạng mảng. Trong NC có $21 \%$ số khối u ngấm thuốc không đồng nhất. Nguyên nhân do các khối u này có thành phần thoái hóa dạng nang, vôi hóa hoặc chảy máu.

Đa số u có bờ đều, chiếm tỷ lệ $67,9 \%$. Theo Lê Thị Hồng Phương (2016), phần lớn UMN có bờ đều, chiếm tỷ lệ $71,9 \%$, u có bờ không đều chiếm $28,1 \%$ [1].

2. Đặc điểm gián tiếp của khối u. Trong NC của chúng tôi, phù não gặp ở $59,3 \%$ tổng số u. Trong đó, đa số gặp phù não độ 1 và độ 2 . Kết quả này tương tự với NC của các tác giả khác [1]. Với UMN, cớ chế phù não có thể được giải thích do các mạch máu nuôi u thường xuất phát từ động mạch cảnh trong, xâm nhập vào màng mềm, từ đó tạo điều kiện vận chuyển dịch ngoại bào trở lại não.

Tỷ lệ không biến đổi xương chiếm 90,1\%. Salah và cs (2019) NC trên 71 trường hợp UMN, có 12/71 trường hợp có hủy xương, chiếm tỷ lế $16,9 \%$ [4], tỷ lệ này cao hơn so với NC của chúng tôi. Biến đổi xương ở UMN gặp cả hủy xương và tăng sinh xương, trong đó tăng sinh xương hay gặp hơn và tỷ lệ có thể lên tới $20 \%$ tổng số u. Các cơ chế bệnh sinh được mô tả bao gồm sự xâm lấn trực tiểp của khối u vào xương và sự tăng sinh phản ứng của màng xương dẫn đến sự hình thành xương lành tính [5].

Trong NC của chúng tôi, tỷ lệ chèn ép xoang tĩnh mạch là 38,3\%. Lê Thị Hồng Phương (2016), tỷ lệ này là $15,8 \%$ [1]. Tỷ lệ chèn ép mach máu trong NC này là $22,2 \%$. Trong NC của Trần Văn Việt (2011), có 11/86 trường hợp có chèn đẩy mạch máu trên hình ảnh $\mathrm{CHT}$, chiếm tỷ lệ 12,8\% [2]. Tỷ lệ trong NC của Lê Thị Hồng Phương (2016) là 10,5\% [1]. Như vậy, tỷ lệ chèn ép xoang cũng như chèn ép mạch máu trong NC của tôi cao hơn so với các tác giả khác. Điều này có thể giải thích do Việt Đức là bệnh viện tuyến cuối nên thường tiếp nhận những trường hợp có chèn ép xoang phức tạp, không giải quyết được ở tuyến dưới.

Trong NC này, tỷ lệ u có chèn ép thần kinh là $28,4 \%$. Tỷ lệ này trong NC của Trần Văn Việt (2011) là 33,3\% [2], tương tự NC của chúng tôi. Trên ảnh T1W dây thần kinh có tín hiệu thấp hoặc trung gian giống nhu mô não, hầu hết dây thần kinh giảm tín hiệu trên các chuỗi xung, với các hướng cắt khác nhau giúp đánh giá sự đè đẩy, chèn ép của UMN vào thần kinh, đặc biệt khối UMN vùng hố yên và nền sọ. 
Trong NC, tỷ lệ chèn ép não thất là 50,4\%. Tỷ lệ này cao hơn so với NC của Lê Thị Hồng Phương (2016) là 36,8\% [1]. Nguyên nhân là do đối tượng trong $\mathrm{NC}$ này là UMN nền sọ, vị trí xa các nã̃o thất và kích thước nhỏ. Đa số UMN trong $\mathrm{NC}$ này không đè đẩy đường giữa, chiếm tỷ lệ $61,7 \%$, tương tự NC của Lê Thị Hồng Phương (2016) là 70,2\% [1].

Dấu hiệu đuôi màng cứng là hình ảnh dày và tăng ngấm thuốc của màng cứng cạnh UMN. Trong NC của chúng tôi, tỷ lệ này là $60,5 \%$. Theo Lê Thị Hồng Phương (2016), tỷ lệ UMN có dấu hiệu đuôi màng cứng là $61,4 \%$ [1]. Kết quả này tương đương với kết quả NC của chúng tôi. Trân Văn Việt (2011) NC trên 86 BN UMN, tỷ lệ này là 41,9\% [2], thấp hơn so với NC của chúng tôi.

\section{KẾT LUÂ̂N}

- Đa số trường hợp là UMN đơn độc, vòm sọ là vị trí hay gặp nhất. U có kích thước đa dạng, trong đó hầu hết là từ $3-6 \mathrm{~cm}$, trung bình là $40,19 \pm 16,45 \mathrm{~mm}$.

- Trên hình ảnh CHT: đa số UMN đồng tín hiệu trên $\mathrm{T} 1 \mathrm{~W}$, tăng nhẹ tín hiệu trên T2W. Sau tiêm, u ngấm thuốc mạnh và đồng nhất. Có $60,5 \%$ khối u có dấu hiệu đuôi màng cứng. Khối u có thành phần vôi hóa, thành phần nang trong u, chảy máu trong u chiếm tỷ lệ thấp. Đa số UMN không gây phù não, hoặc chỉ gây phù não mức độ nhẹ.
- Ngoài ra, CHT giúp đánh giá mức độ chèn ép, xâm lấn tổ chức xung quanh của UMN. Tỷ lệ UMN gây biến đổi xương cạnh u rất thấp, chiếm 9,9\% tổng số khối u. Trong NC có 38,3\% tổng số khối u có chèn ép xoang tĩnh mạch. Tỷ lệ UMN chèn ép mạch máu và thần kinh lần lượt là $22,2 \%$ và $28,4 \%$.

\section{TÀI LIÊU THAM KHẢO}

1. Lê Thị Hồng Phương (2016). Đặc điểm hình ảnh cộng hưởng từ và mối liên quan với triệu chứng lẩm sàng của u màng não nên sọ. Luận văn tốt nghiệp Bác sĩ Nội trú, Đại học Y Hà Nội.

2. Trân Văn Việt (2011). Nghiên cứu giá trị chụp cộng hưởng tữ, chụp mạch số hóa xóa nền trong chẩn đoán và điều trị u màng não. Luận án Tiến sỹ Y học, Đại học Y Hà Nội.

3. Nguyễn Minh Thuận (2019). Mô tả đắc điểm lâm sàng, chẩn đoán hình ảnh và đánh giá kết quả điều trị phẫu thuật bước đầu u màng não vòm sọ tai bênh viên K. Thac sỹ, Đai họ Y Hâ Nối.

4. F. Salah, A. Tabbarah, N. Alarab y. et al. (2019), "Can CT and MRI features differentiate benign from malignant meningiomas?". Clinical Radiology, 74(11), pp. 898.e15-898.e23.

5. J. Watts, G. Box, A. Galvin. et al. (2014) "Magnetic resonance imaging of meningiomas: a pictorial review". Insights Imaging, 5(1), pp. 113-22.

6. Antonios Drevelegas (2010), Imaging of brain tumors with histological correlations,Springer Science \& Business Media

7. T. Zhang, J. M. Yu, Y. Q. Wang. et al. (2018), "WHO grade I meningioma subtypes: MRI features and pathological analysis". Life Sci, 213, pp. 50-56.

\title{
THAY KHỚP KHUỶU ĐIỀU TRI MẤT VẬN ĐộNG KHUỶU DO DI CHỨNG CHẤN THƯƠNG, 3 CA LÂM SÀNG
}

\author{
Trần Quyết ${ }^{1}$, Trần Trung Dũng ${ }^{1,2}$, Nguyễn Trần Quang Sáng ${ }^{1}$, \\ Phạm Trung Hiếu ${ }^{1,2}$, Vũ Tú Nam ${ }^{1,2}$, Võ Sỹ Quyền Năng ${ }^{1}$, \\ Trần Đức Thanh ${ }^{1}$, Phan Khoa Nguyên ${ }^{1}$
}

\section{TÓM TẮT}

Chúng tôi báo cáo 3 ca lâm sàng thay khớp khuỷu toàn phần điều trị mất vận động khuỷu do di chứng chấn thương. Trong đó có 1 ca cứng khớp khuỷu ở tư thế khuỷu duỗi 30 độ, 1 ca cứng ở tư thế khuỷu duối 25 độ, 1 ca mất vững khớp khuỷu. Độ tuổi trung bình là 35, thời gian theo dõi sau mổ trung bình là 4 tháng.

\footnotetext{
${ }^{1}$ Bệnh viện đa khoa Tâm Anh

${ }^{2}$ Trường đại học Y Hà Nội

Chịu trách nhiệm chính: Trân Quyết

Email: quyettran.bs@gmail.com

Ngày nhận bài: 10.5.2021

Ngày phản biên khoa học: 28.6.2021

Ngày duyệt bài: 6.7.2021
}

Kết quả sau mổ biên đô khớp khuỷu gấp trung bình đạt 113 độ, duối trung bình thiếu 3 độ, sấp cẳng tay chủ động 73 độ, ngửa cẳng tay chủ động 53 độ, thang điểm đánh giá chức năng khớp khuỵu Mayo [3] đạt mức rất tốt với 95 điểm. Cả 3 bệnh nhân đêu hoàn toàn hài lòng với kết quả sau phẫu thuât. Có nhiều báo cáo về các ca thay khớp khuỷu điều trị hạn chế vân đông khuỷu do di chứng chấn thương đều cho kểt quả khả quan với việc cải thiện tầm vận động khớp khuỷu ở các mức đô khác nhau. ở Viêt Nam thay khớp khuỷu vẫn là phương pháp điêu trị hoàn toàn mới. Để có kết quả tốt nhất cần có kế hoạch chuẩn bị trước mổ và quản lý bệnh nhân sau mổ một cách toàn diên.

Tư khóa: Thay khớp khuỷu toàn phân, mất vận động khuỷu, di chứng chấn thương. 